\title{
URINARY OUTPUT OF ADRENALINE AND NORADRENALINE DURING ANAESTHESIA AND SURGERY: PRELIMINARY STUDY
}

\author{
Turan Ozdil, M.D., AND W. Forrest Powerl, M.D.
}

SYMPTHO-ADRENAL MEDULLARY ACTIVITY during anaesthesia has been studied fluorometrically, measuring catechol amines in peripheral and adrenal vein blood. ${ }^{1-5}$ Results of these studies indicated that light anaesthesia did not produce any significant rise in catechol amines, whereas deeper planes of anaesthesia employing ether, cyclopropane, chloroform, and vinyl ether produced significant increases in blood levels of adrenaline and noradrenaline; halothane caused little or no change; thiopentone administration resulted in no change or a decrease in blood levels. One of the investigators ${ }^{6}$ found decreased blood levels in deeper planes with cyclopropane and halothane.

Periodic determination of blood levels of adrenaline and noradrenaline is a useful method for relating changes in depth of anaesthesia to the output of these hormones, and it also indicates total body output. The quantity of urinary output of adrenaline and noradrenaline seems to parallel the total body output, ${ }^{7,8}$ Therefore, determinations of urinary output should reflect the over-all changes in total body output during anaesthesia and surgery.

\section{General}

\section{METHOD}

The urine values of adrenaline and noradrenaline were studied in fifteen patients, male and female, who were to undergo a variety of surgical procedures. Their ages ranged from seventeen to seventy-three years. Conventional preoperative sedation (barbiturates, demerol, and atropine or scopolamine) was used. All patients were alert and co-operative. The bladder was emptied by catheterization just prior to induction, and the sample discarded. Collections were begun simultaneously with the induction of anaesthesia, and were stopped at the end of anaesthesia. Lumbar epidural analgesia, unsupplemented, was used for two procedures, and general anaesthesia was employed for the others. Technique for the latter consisted of a sleep dose of intravenous thiopentone followed by the inhalation agent and a subsequent single dose of succinylcholine to facilitate intubation. Patients were kept in light planes of anaesthesia, a succinylcholine drip was used to produce muscle relaxation when needed, and respirations were assisted or controlled to keep arterial $P_{\mathrm{O}_{2}}$ and $P_{\mathrm{CO}_{2}}$ normal. Patients were observed closely for clinical signs of sympathetic nervous system activity.

-The University of Tennessee Memorial Research Center and Hospital, Knoxville, Tennessee. 


\section{Preparation of Urine Extracts}

Urine extracts were prepared as adapted by Goodall ${ }^{7}$ from von Euler and Heller, ${ }^{9,10}$ The urine was hydrolysed, and the adrenaline and noradrenaline were selectively adsorbed on aluminum hydroxide and filtered. The precipitate was washed and redissolved with $2 N$ sulphuric acid. The remaining salts were precipitated out by mixing the extract with alcohol and acetone. Filtrate was concentrated in vacuo.

Biological assay. (a) Cat's blood pressure was recorded from the carotid artery, and injections of adrenaline, noradrenaline, and urinary extract were made into the femoral vein.

(b) Fowl's rectal cecum. Two to three centimeters of the hen's rectal cecum was suspended in Tyrode's solution at $39^{\circ} \mathrm{C}$. Carbon dioxide 6.5 per cent in oxygen was bubbled through the solution. Injections of adrenaline, noradrenaline, and urinary extract were made into the bath, and the degree of cecal relaxation was recorded.

Computation of results. Having determined the activity ratio for adrenaline and noradrenaline by these methods, and the activity of the unknown urinary extract in terms of 1-noradrenaline, it is possible to calculate the relative amounts of adrenaline and noradrenaline in the urinary extract. The following symbols are used for such calculation:

$a=1$-noradrenaline equivalents in micrograms per $\mathrm{ml}$. of urine on cat's blood pressure.

$A=1$-noradrenaline equivalents in micrograms per ml. of urine on hen's rectal cecum.

$q=$ Activity ratio l-adrenaline : l-noradrenaline on cat's blood pressure.

$Q=$ Activity ratio 1-adrenaline : 1-noradrenaline on hen's rectal cecum.

The amount of 1-adrenaline and I-noradrenaline may then be calculated as follows:

$$
\begin{aligned}
& X=\text { micrograms } / \mathrm{ml} \text {. of adrenaline, or }(A-a) /(Q-q), \\
& Y=\text { micrograms } / \mathrm{ml} \text {. of noradrenaline or } A-X Q .
\end{aligned}
$$

In these studies, the amount of adrenaline and noradrenaline in one $\mathrm{ml}$. of urine was calculated and multiplied by total urine output for the collection period. The result was extrapolated for twenty-four hour output. Because of increased urinary output of catechol amines secondary to preoperative excitement, we compared our results with the normal urinary output of adrenaline and noradrenaline as determined by Goodall and Haynes ${ }^{7}$ with the same bioassay method. We used the bioassay method of catechol-amine determination because it is considered more accurate than the fluorometric or colorimetric methods, ${ }^{7-10}$ since adrenaline and noradrenaline precursors, amino acids, and other constituents are fluorometrically active.

\section{Results and Discussion}

The results obtained are shown in Tables I, II, III, and IV. As seen in the tables, our average results, like the results obtained by others, ${ }^{1-6}$ do not reveal any significant change from normal during epidural analgesia or during light 
TABLE I

Cyclopropane

\begin{tabular}{|c|c|c|c|c|c|}
\hline \multirow[b]{2}{*}{ No. } & \multirow[b]{2}{*}{ Age } & \multirow[b]{2}{*}{ Sex } & \multirow[b]{2}{*}{ Procedure } & \multicolumn{2}{|c|}{ Calculated $\mu \mathrm{g} . / 24$ hours } \\
\hline & & & & adrenaline & noradrenaline \\
\hline $\begin{array}{l}1 \\
2 \\
3 \\
4 \\
5\end{array}$ & $\begin{array}{l}61 \\
63 \\
17 \\
42 \\
48\end{array}$ & $\begin{array}{l}F \\
F \\
F \\
F\end{array}$ & $\begin{array}{l}\text { colectomy } \\
\text { colectomy } \\
\text { pelvic laparotomy } \\
\text { abdominal hysterectomy } \\
\text { thyroidectomy }\end{array}$ & $\begin{array}{r}11.3 \\
18.0 \\
9.1 \\
1.1 \\
21.6\end{array}$ & $\begin{array}{l}21.4 \\
15.2 \\
24.0 \\
21.1 \\
40.4\end{array}$ \\
\hline \multicolumn{4}{|c|}{ Average normal } & 15.7 & 32.3 \\
\hline
\end{tabular}

TABLE II

ETHER

\begin{tabular}{cccccc}
\hline \hline & & & \multicolumn{2}{c}{ Calculated $\mu g . / 24$ hours } \\
\cline { 3 - 6 } No. & Age & Sex & & Procedure & adrenaline noradrenaline \\
\hline 6 & 30 & M & teeth extraction & 10.1 & 10.7 \\
7 & 71 & M & gastrectomy & 14.9 & 16.5 \\
8 & 45 & F & mitral valvulotomy & 20.7 & 23.5 \\
\multicolumn{2}{l}{ Average normal } & & 15.7 & 32.3 \\
\hline
\end{tabular}

TABLE III

HaLoThaNe

\begin{tabular}{rrrrrr}
\hline \hline & & & \multicolumn{2}{c}{ Calculated $\mu g . / 24$ hours } \\
\cline { 3 - 6 } No. & Age & Sex & & Procedure & adrenaline noradrenaline \\
\hline 9 & 66 & M & laparotomy & 9.4 & 22.5 \\
10 & 30 & M & laminectomy & 15.2 & 16.1 \\
11 & 73 & M & excision ca. of ear & 18.1 & 27.6 \\
12 & 38 & $\mathrm{~F}$ & teeth extraction & 2.9 & 84.4 \\
13 & 50 & $\mathrm{M}$ & gastrectomy & 17.2 & 20.5 \\
\multicolumn{3}{l}{ Average normal } & & 15.7 & 32.3 \\
\hline
\end{tabular}

TABLE IV

EpIDURAL

\begin{tabular}{lccccc}
\hline \hline & & & \multicolumn{2}{c}{ Calculated $\mu \mathrm{g} . / 24$ hours } \\
\cline { 4 - 5 } No. & Age & Sex & Procedure & adrenaline noradrenaline \\
\hline 14 & 53 & $\mathrm{M}$ & herniorraphy & 5.5 & 39.9 \\
15 & 46 & $\mathrm{M}$ & herniorraphy & $\mathbf{2 0 . 2}$ & 25.1 \\
\multicolumn{3}{l}{ Average normal } & & 15.7 & 32.3 \\
\hline
\end{tabular}


anaesthesia with cyclopropane, ether, or halothane. Further investigations are necessary to determine the effects of deep anaesthesia and high arterial $P_{\mathrm{CO}_{2}}$ on urinary output of catechol amines. Because of discrepancies between the results obtained from blood levels of adrenaline and noradrenaline during deep anaesthesia by different investigators, ${ }^{1-6}$ simultaneous determinations of blood concentrations and urinary output of catechol amines may give a better understanding of their alteration related to the depth of anaesthesia.

\section{SUMMARY}

Urinary output of adrenaline and noradrenaline was determined in fifteen surgical patients. Two received epidural analgesia and thirteen received light anaesthesia employing cyclopropane, ether, or halothane as the main agent. Results did not show a significant change from the normal urinary output of adrenaline and noradrenaline in any group.

\section{ACKNOWLEDGMENTS}

We wish to express our sincere appreciation to McC. Goodall, M.D., for his valuable advice and guidance in this study, and to Mrs. Sarah Smith for her excellent technical laboratory assistance.

\section{REFERENCES}

1. Hamelazac, W.; Sprouse, J. H.; Mahafrey, J. E.; \& Ruchardson, J. A. Catechol Amine Level during Light and Deep Anesthesia. Anesthesiology 21: 297 (1960).

2. Price, H. L.; Linde, H. W.; Jones, R. E.; Brack, G. W.; \& Pruce, M. L. SympathoAdrenal Responses to General Anesthesia in Man and their Relation to Hemodynamics. Anesthesiology 20: 563 (1959).

3. Richardson, J. A.; Woods, E. F.; \& Rrchardson, A. K. Plasma Concentrations of Epinephrine and Norephinephrine during Anesthesia. J. Pharmacol. \& Exper. Therap. 119: 378 (1957).

4. Pruce, H. L. Circulating Adrenaline and Noradrenaline during Diethyl Ether Anaesthesia in Man. Clin. Sci. 16: 377 (1957).

5. Woods, E. F.; Ruchardson, J. A.; Richardson, A. K.; \& Boxoman, R. J., Jr. Plasma Concentrations of Epinephrine and Arterenol Following Actions of Various Agents on Adrenals. J. Pharmacol. \& Exper. Therap. 116: 351 (1956).

6. Carnes, M. A.; McPhall, J. L.; Fabian, L. W.; \& Hardy, J. D. Adrenergic and Adrenocortical Responses to Fluothane and Cyclopropane. Am. Surgeon. 27: 223 (1961).

7. Goodall, McC.; Stone, C.; \& Haynes, B. W., JR. Urinary Output of Adrenaline and Noradrenaline in Severe Thermal Burns. Ann. Surg. 145: 479 (1957).

8. voN EuLER, U. S. Noradrenaline. Springfield: Thomas (1955).

9. - Preparation, Purification and Evaluation of Noradrenaline and Adrenaline in Organ Extracts. Arch. Internat. Pharmacodyn. 77: 477 (1948).

10. von Euler, U. S. \& Heller, S. Excretion of Noradrenaline, Adrenaline and HydroxyTyramine in Urine. Acta. physiol. scandinav. 22: 161 (1951). 